\title{
Assessment of Radiation Shielding Properties of Polymer-Lead (II) Oxide Composites
}

\author{
M. A. Salawu ${ }^{\text {a,* }}$ J. A. Gbolahan ${ }^{\text {a }}$, A. B. Alabi ${ }^{\mathrm{a}}$ \\ ${ }^{a}$ Department of Physics, University of Ilorin, Ilorin, Nigeria
}

\begin{abstract}
Long term exposure to very high levels of radiations from medical diagnostic centres, industries, nuclear research establishments and nuclear weapon development have resulted in health effects such as cancer and acute radiation syndrome, hence the need for proper radiation shielding. This paper investigated Epoxy-Lead (II) Oxide ( $\mathrm{PbO}$ ) composite as radiation shielding. The composites were prepared by dispersion of microsized $\mathrm{PbO}$ particles into polymeric materials using effective melt-mixing method and cast in a $4 \mathrm{~cm}$ by $6 \mathrm{~cm}$ rectangular aluminium Mold with a thickness of $5 \mathrm{~mm}$ and was allowed to set over night at room temperature. The gamma ray attenuation ability of the composites were studied using gamma ray transmission or attenuation coefficient determination for the gamma ray energy. Three gamma ray sources Ba-133, Cs-137 and Co-60 were employed. The density, linear attenuation coefficient, half value layer (HVL), relaxation length and heaviness of the samples were determined. The measured values of linear attenuation coefficient increased with increasing filler concentration in all the samples at all gamma ray energies. It was also noticed that $40 \%$ and $50 \%$ filler samples attenuates more relative to the other samples under study. The maximum linear attenuation attained was found at energy of $662 \mathrm{keV}$. The composites have been found to possessed medical gamma-ray attenuation characteristics among the sample materials over a certain photon energy range $(0.08 \mathrm{MeV}-1.332 \mathrm{MeV})$ and found useful as a biological radiation shielding against gamma rays.
\end{abstract}

DOI:10.46481/jnsps.2021.249

Keywords: PbO, PANI, HVL, Epoxy, attenuation

Article History :

Received: 12 June 2021

Received in revised form: 17 August 2021

Accepted for publication: 18 August 2021

Published: 29 November 2021

(C)2021 Journal of the Nigerian Society of Physical Sciences. All rights reserved. Communicated by: E. Etim

\section{Introduction}

Electromagnetic radiation like gamma beams and $\mathrm{x}$-beams are risky to human wellbeing. Individuals get exposed to gamma and $\mathrm{x}$-radiations from various kinds of sources including industries, medical diagnostic centres, nuclear research establishments, nuclear reactors, research involving radio-isotopes and nuclear weapon development facilities.

\footnotetext{
${ }^{*}$ Corresponding author tel. no: +2348030788553

Email address: salawu.ma@unilorin.edu.ng, abideen2004@gmail.com (M. A. Salawu)
}

To shield work force and delicate electronic gear from such ionizing radiation, protection is important. Radiation protection is the act of shielding individuals and the environment from unsafe impact of ionizing radiation. Radiation exposure is one of the significant concerns when setting up thermal energy stations, the utilization of solid (high action) Poly Aniline (PANI) discover application in strong erosion safe materials, electrical apparatuses, electrolytes for batteries and electromagnetic protecting materials.

Lead is the most well-known protecting material used to 
shield against gamma beam and $\mathrm{x}$-beams. Be that as it may, the presence of a quickly changing attractive field in these radiations prompts whirlpool current in a conductor. Thus, the utilization of standard metallic lead gets unsatisfactory. Accordingly, it is attractive that the protecting material ought to be a non-conductor. This necessity is very much fulfilled by utilizing different mixes of metal powders in a polymer grid.

Composites are materials that contain solid burden conveying material (known as reinforcement) imbedded in a more vulnerable material known as matrix [1]. Polymeric composites containing different measures of inorganic added substances have been widely read by a few specialists to contemplate the protecting properties toward gamma and x-radiation $[2,3,4,5$, $6,7,8,9,10,11,12,13,14,15,16,17,18,19,20,21,22,23]$. The added substances might be any of the fitting high-electron thickness materials, for example, lead oxides, lead silicate, lead sulfide, and so forth, scattered in a plastic matrix or materials containing lead acrylate. Lead material is dense and has radiation that can be employed against different forms of highenergy applications of radiation such as gamma rays, x-rays, and other types of nuclear radiation.

In this study, the gamma ray attenuation ability of the fabricated composites was studied by means of gamma ray transmission or attenuation. coefficient determination for the gamma ray energy. This was performed by using three gamma ray sources which are Ba-133, Cs-137 and Co-60. The sample preparation was based upon the dispersion of micro-sized particles into polymeric materials by an accurate and effective melt-mixing method which was becoming increasingly important so that a uniform mixture could be produced.

\section{Materials and methods}

Epoxy resin (bisphenol-A-diglycidyl ether poly), hardener (isophoromediamine) and filler (lead (II) oxide powder) of commercial grade were used with the modification of the method reported by [24]. The sample preparation was based upon the dispersion of particles into polymeric materials by melt-mixing methods. Micron-sized $\mathrm{PbO}$ was added into the epoxy resin before the hardener was mixed into it. The ratio of epoxy resin to hardener used was $2: 1$. The mixing of $\mathrm{PbO}$ powder in epoxy resin was stirred thoroughly using a two-roll Rheomixer device and a rotor speed of 60 revolution per minutes (rpm) for $10 \mathrm{~min}$ utes to ensure fairly uniform dispersion of the powder in epoxy matrix. The well-mixed mixture was then cast in a $4 \mathrm{~cm}$ by 6 $\mathrm{cm}$ rectangular aluminium mold with a thickness of $5 \mathrm{~mm}$ and was allowed to set over night at room temperature. The density, linear attenuation coefficient, half value layer (HVL), relaxation length and heaviness of the samples were determined. The apparent density of prepared samples was measured using:

$$
\rho=\frac{M}{V},
$$

where $M$ and $V$ are the mass and volume of each sample, respectively.
The measured densities were compared with the theoretical values, (with an assumption that the samples were free from voids) which are determined using:

$$
\rho_{c}=\frac{100}{\left[\frac{E}{\rho_{f}}-\frac{E}{\rho_{e}}\right]}
$$

where $E$ is the weight $\%$ of epoxy, $\rho_{f}$ is the density of filler, and $\rho_{e}$ is the density of epoxy.

Gamma ray transmission through the prepared samples was studied using beam of well collimated point source from Co60, Cs-137, Ba-133. The initial intensity (Io) of the generated gamma-rays was determined. The distance between the source and the detector was set to be $6.6 \mathrm{~cm}$. Then the transmitted gamma-ray beam (I) was measured with the sample placed in front of the detector. For each composite sample, the measurements were performed three times. The linear attenuation coefficient for each sample was then calculated using:

$$
\mu=\frac{\ln \frac{I_{0}}{I}}{x}
$$

where $x$ is the thickness of the sample, $I_{0}$ is initial intensity of the gamma ray, $I$ is the transmitted intensity with shielding. Figure 1 shows the schematic diagram of the set up.

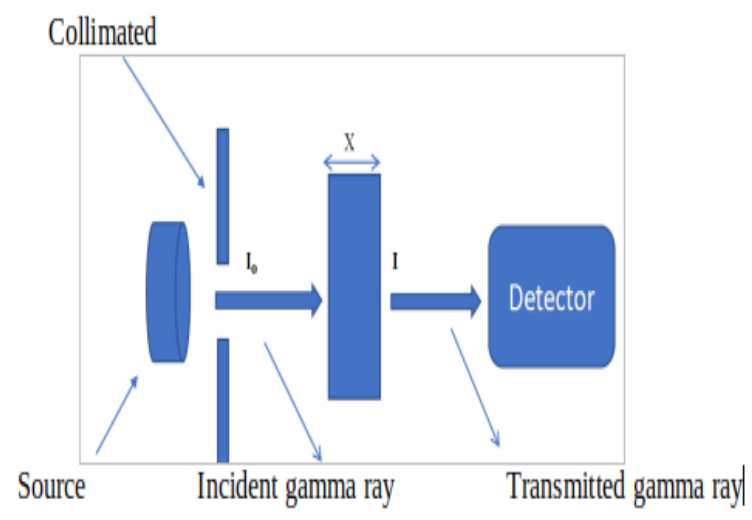

Figure 1: Schematic setup of experiment.

The mass attenuation coefficient was determined using:

$$
\mu_{m}=\frac{\mu}{\rho_{c}}
$$

where $\mu$ is linear attenuation and $\rho_{c}$ is theoretical density.

The Half Value Layer (HVL), relaxation length and \% of heaviness were respectively determined using equations (5), (6) and (7), respectively.

$$
H V L=\frac{0.693}{\mu},
$$

$$
\text { Relaxation length } \lambda=\frac{1}{\mu}
$$


where $\mu$ is the linear attenuation of the absorber. With reference to lead, the $\%$ of heaviness of other conventional shielding materials along with epoxy $+\mathrm{PbO}$ composites was evaluated using equation (7).

$$
\% \text { of heaviness }=\frac{\text { Density of material }}{\text { Density of lead }} \times 100
$$

\section{Results and Discussion}

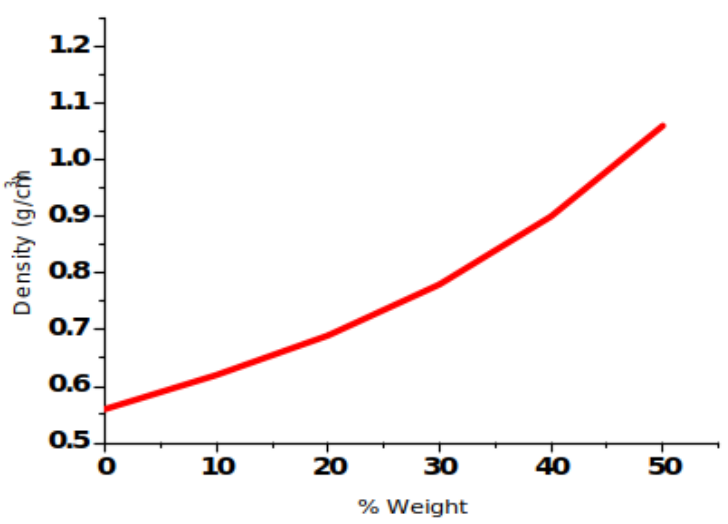

Figure 2: Density against the percentage weight of the sample

The density of the samples increases as the percentage weight of the samples increases. The densities ranges from $0.55 \mathrm{~g} / \mathrm{cm}^{3}$ to $1.1 \mathrm{~g} / \mathrm{cm}^{3}$ from 0 to 50 percentage weight.

Table 1 and Figure 3 illustrate the relationship between linear attenuation coefficient and weight percent of the filler of the composites for Ba-133, Cs-137 and Co-60 gamma sources. The measured values of linear attenuation coefficient increased with increasing filler concentration in all the samples at all gamma ray energies and is in good agreement with the reported works of $[24,25]$. The linear attenuation coefficient ranges between 1.0773 to 2.9833 for Ba-133, 4.9945 to 7.2121 for Cs-137 and 0.3942 to 0.9486 for Co-60 gamma sources.

Figure 4 shows the linear attenuation coefficient against energy for the samples under study. It was noticed that $40 \%$ and $50 \%$ filler samples attenuate more than the rest of the samples. The maximum attenuation attained was found to be at

Table 1: Linear attenuation coefficient $(\mu)$ of the samples for each Gamma Source.

\begin{tabular}{lllll}
\hline \hline S/N & $\begin{array}{l}\text { Filler \% in } \\
\text { sample }\end{array}$ & \multicolumn{3}{c}{ Linear Attenuation $(\mu)$} \\
\hline \hline & & Ba-133 & Cs-137 & Co-60 \\
1 & 0 & 1.0773 & 4.9945 & 0.3942 \\
2 & 10 & 2.0877 & 5.1310 & 0.5467 \\
3 & 20 & 2.1472 & 5.2417 & 0.6125 \\
4 & 30 & 2.2455 & 5.4956 & 0.7190 \\
5 & 40 & 2.8388 & 7.1113 & 0.8981 \\
6 & 50 & 2.9833 & 7.2121 & 0.9486 \\
\hline \hline
\end{tabular}

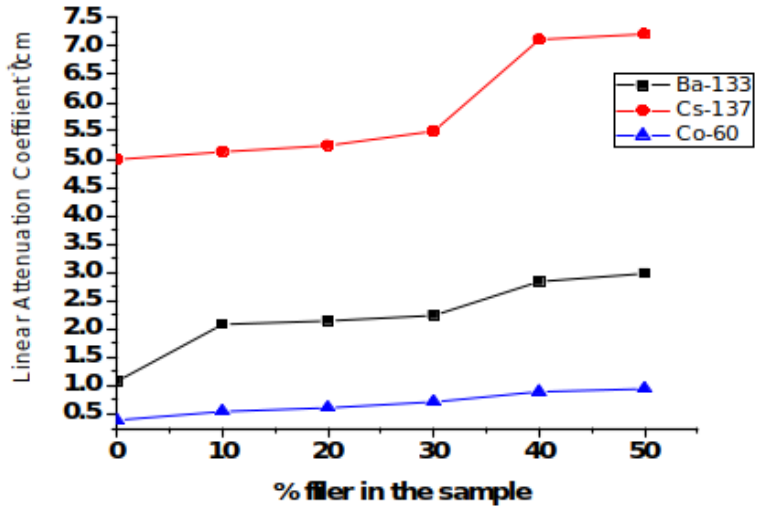

Figure 3: Linear attenuation coefficient against $\%$ filler in the sample

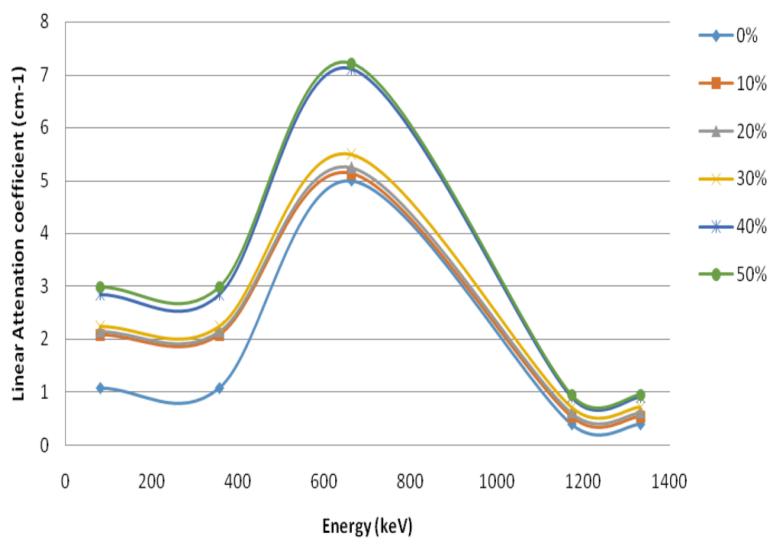

Figure 4: Linear attenuation coefficient $\left(\mathrm{cm}^{-1}\right)$ against Energy $(\mathrm{keV})$

energy $662 \mathrm{keV}$ as shown in Figure 4. The shielding materials attenuates single energy more than the double range energies sources. Linear attenuation decreased at $80 \mathrm{keV}$ to around 400 $\mathrm{keV}$ and optimum at $662 \mathrm{keV}$ and decreases down as the energy increases to $1332 \mathrm{keV}$. This is due to the fact that linear attenuation was pronounced for single energy sources and less for bi-energy source. At $662 \mathrm{keV}$ energy, linear attenuation coefficient values was noticed to have increased due to Cs-137 being single energy source and having low activity of $0.25 \mu \mathrm{Ci}$.

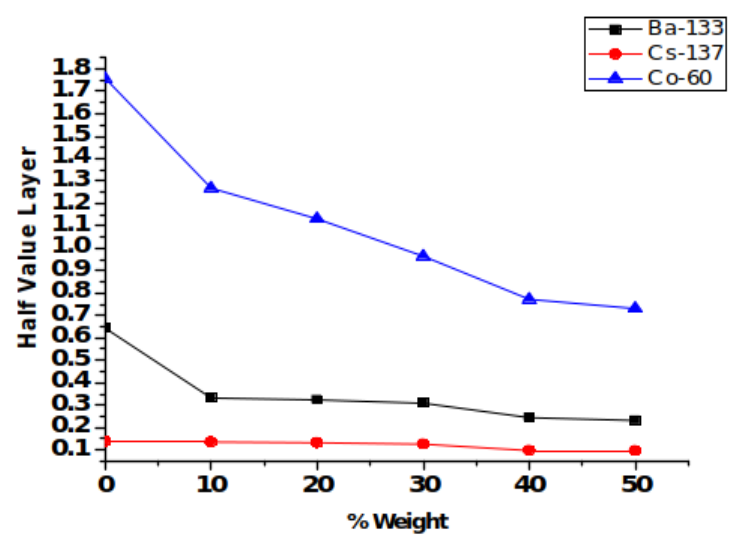

Figure 5: Half Value Layer against \% weight 
Figure 5 shows the Half Value Layer against \% weight for the samples under study. The Half Value Layers (HVLs) for the samples are seen to have small values for Cs-137 and Ba-133 gamma radiations relative to Co-60. Also the significant reduction in values of HVLs for Cs-137 may be due to it being single energy source. The HVLs also decreases with increasing filler content. Therefore, it requires a thickness of $0.731 \mathrm{~cm}, 0.096$ $\mathrm{cm}, 0.23 \mathrm{~cm}$ of $50 \%$ filler to reduce the radiation intensity coming from gamma sources Co-60, Cs-137, and Ba- 133 to $50 \%$ respectively.

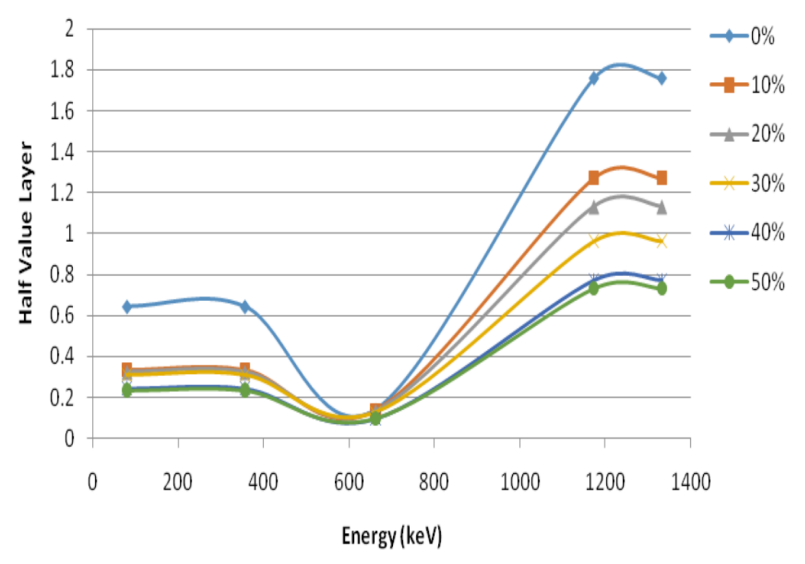

Figure 6: Half Value Layer against Energy (keV).

Figure 6 illustrates the relationship between HVL and energy. It was found that the HVLs of the composite samples behaves differently at different energies of the gamma radiation. The HVL decreased significantly at $662 \mathrm{keV}$ and has optimum value at $1200 \mathrm{keV}$ for all the samples under study. The

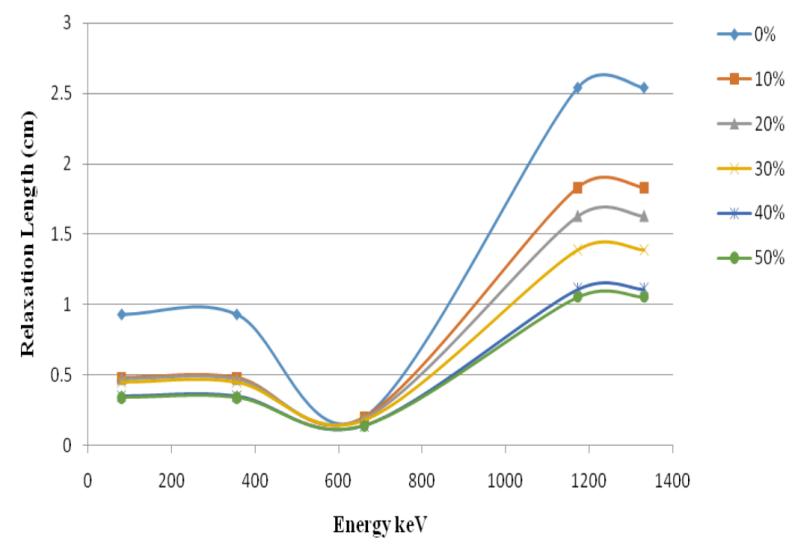

Figure 7: Relaxation length against the Energy (keV) for different weight percent filler in the Samples.

relaxation length $(\lambda)$ is calculated from linear attenuation coefficient $(\mu)$ of all the samples at an energy range of $80 \mathrm{keV}-1332$ $\mathrm{keV}$ and it changes with photon energy as shown in Figure 7. The relaxation length $(\lambda)$ of any particular radiation represents the average distance between two successive interactions. The less the relaxation length of a material at a particular energy, the better the shielding properties it possesses. Mathematically, the relaxation length $(\lambda)$ is equivalent to the reciprocal of lin- ear attenuation coefficient $(\mu)$. It is observed that at $662 \mathrm{keV}$ energy, the relaxation length is relatively low relative to other energy sources. This indicates that the composites will be a good shielding material at $662 \mathrm{keV}$. The low energy photons loses their energy in a short distance while high energy photons need a longer distance to lose their energy. Figure 8 shows

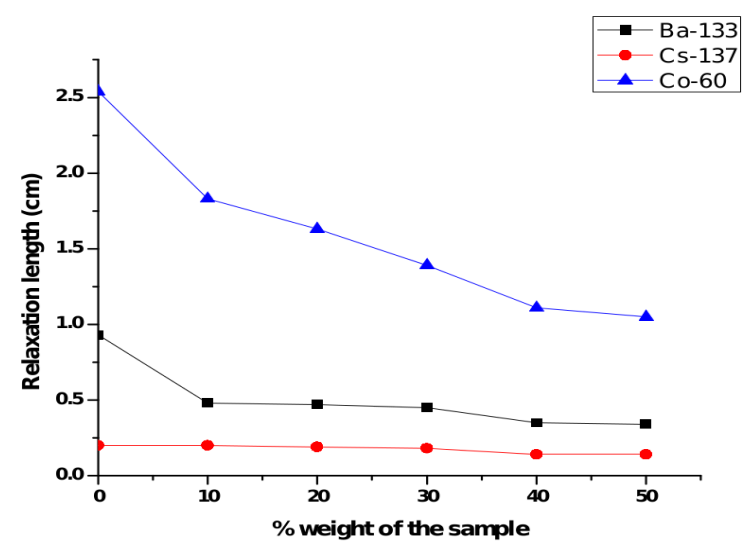

Figure 8: Relaxation Length against \% weight of the samples

the Relaxation Length against \% weight of the sample. The relaxation length decreased with increased in filler content of the samples. This is as a result of increase in densities of the samples thereby causing the distances between the particles in the samples to decrease.

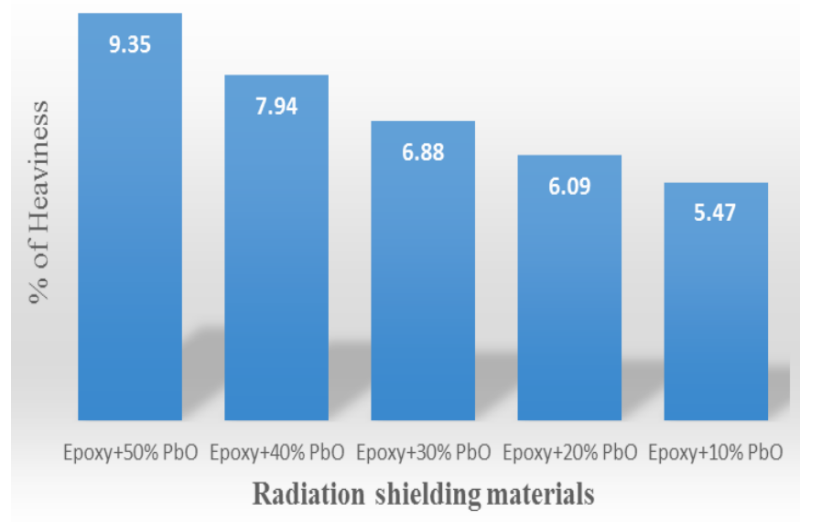

Figure 9: Relaxation Length against \% weight of the samples

Figure 9 shows the $\%$ of heaviness of each of the $\%$ weight composition of Epoxy $\mathrm{PbO}$. The results obtained proved that the polymer composites considered exhibits excellent lightness relative to conventional radiation shielding materials such as Lead, Barite, Steal, Concrete Lead Glass, whose \% heaviness ranges between 54.85 and 100. At the same time, their performance as radiation shielding materials are appreciable particularly at higher concentrations and for low energy gamma ray sources.

Figure 10 shows the Scanning Electron Microscope (SEM) micrographs of $\mathrm{PbO}$ epoxy filled composites for (a) pure epoxy (b) $10 \%$ filler (c) $20 \%$ filler (d) $30 \%$ filler (e) $40 \%$ filler and (f) $50 \%$ filler. The micrographs showed uniform distributions 


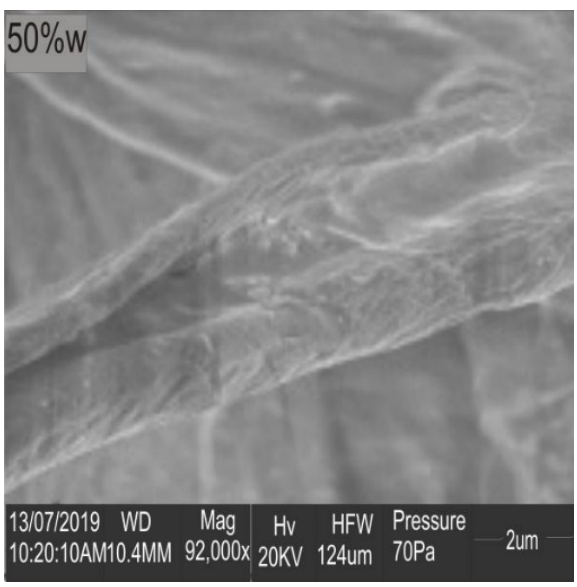

(a)

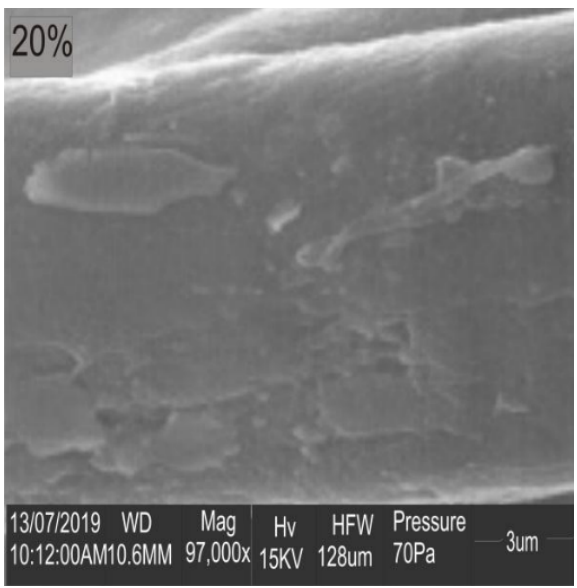

(c)

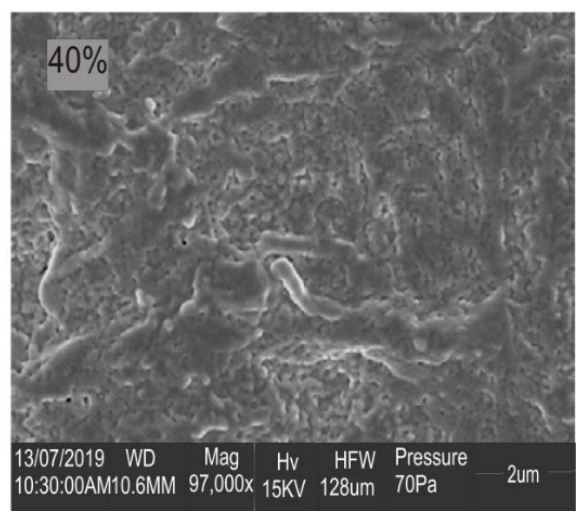

(e)

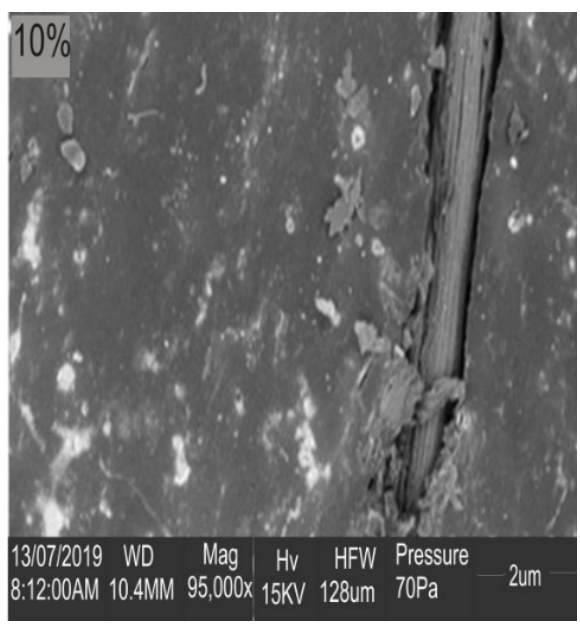

(b)

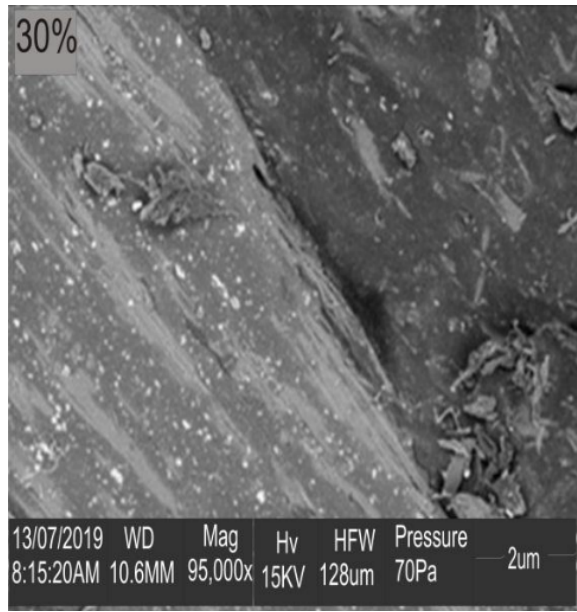

(d)

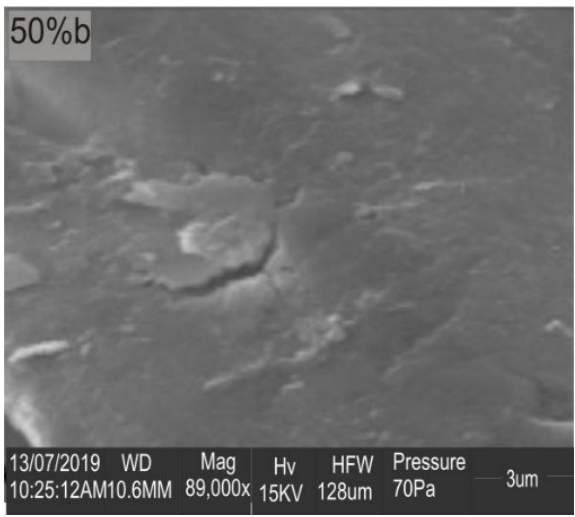

(f)

Figure 10: Scanning Electron Microscope (SEM) micrographs of fabricated samples

of the filler within the matrix (Figure 10a to 10f). The bright regions represent the filler particles $(\mathrm{PbO})$ dispersed in the dark epoxy matrix. The fillers were seen to be quite uniformly dispersed in the composites, although with minor agglomerations.

\section{Conclusion}

The measured values of linear attenuation coefficient increased with increasing filler concentration in all the samples at all gamma ray energies. The $40 \%$ and $50 \%$ filler samples attenuate more gamma ray relative to the other samples under study. The maximum linear attenuation attained was found to be at energy of $662 \mathrm{keV}$. This locally developed shielding material, Epoxy-Lead (II) oxide ( $\mathrm{PbO}$ ) composite has been found to 
possesses medical gamma-ray attenuation characteristics among the sample materials over a certain photon energy range $(0.08$ $\mathrm{MeV}-1.332 \mathrm{MeV}$ ) and at this energy range, it can be used as a biological radiation shielding against gamma rays. The low cost, availability of raw materials and ease of fabrication makes the composites an excellent radiation shielding material.

\section{References}

[1] A.B. Alabi, M. A. Salawu, R. A. Jimoh \& T. Akomolafe, "Appraisal of mechanical properties of different particle sizes of palm kernel shell, coconut shell and mixed palm kernel-coconut shells particles epoxy-filled composites", Sri Lankan Journal of Physics 21 (2020) 1.

[2] M. A. Abdel-Rahman, E. A. Badawi, Y. L. Abdel-Hady \& N. Kamel, "Effect of Sample Thickness on the Measured Mass Attenuation Coefficients of some Compounds and Elements for 59.54, 661.6 and $1332.5 \mathrm{keV}$ gamma-rays", Nuclear Instruments and Methods in Physics Research A 447 (2000) 432.

[3] A. Akkas, "Determination of the Tenth and Half Value Layer Thickness of Concretes with Different Densities", Acta Physica Polonica A. 129 (2016) 770.

[4] J. C. Khong, D. Daisenberger, G. Burca, W. Kockelmann, A. S.Tremsin \& J. Mi1, "Design and Characterisation of Metallic Glassy Alloys of High Neutron Shielding Capability", Scientific Reports 6 (2016) 36998, DOI: $10.1038 /$ srep36998

[5] M. R. Ambika, N. Ambika, V. Harish, N. K. Lokanath, M. A. Sridhar, N. M. Renukappa \& S. K. Suman. "Preparation and Characterization of Isophthalic-Bi2O3 Polymer Composite Gamma Radiation Shields", Radiation 130 (2017) 351, http://dx.doi.org/10.1016/j.radphysch em.2016.09.022.

[6] G. Antonio, R. De Santis \& L. Ambrosio, "Polymer-Based Composite Scaffolds for Tissue Engineering", Journal of Applied Biomaterials \& Biomechanics 8 (2010) 57.

[7] S. A. Bello, J. O. Agunsoye, B.,M.S. Hassan, G. Z. Kana \& I. A. Raheem, "Epoxy Resin Based Composites, Mechanical and Tribological Properties", Tribology in Industry 37 (2015) 500.

[8] R. Biswas, H. Sahadath, A. S. Mollah \& Md. H. Fazlul, "Calculation of Gamma-ray Attenuation Parameters for Locally Developed Shielding Material, Polyboron", Journal of Radiation Research and Applied Sciences 9 (2016) 26.

[9] B. Buyuk \& A. B. Tugrul, "Comparison of lead and WC-Co Materials Against Gamma Irradiation" Acta Physica Polonica A 125 (2014) 423.

[10] Campbell F. C, "Structural Composite Materials", ASM International 1 (2010) 1.

[11] A. Eid Gh, A. I. Kany, M. M. El-Toony, A.M. Madbouly, I. I. Bashter \& F. A. Gaber, "Application of Epoxy/ Pb3O4 Composite for Gamma Ray
Shielding”, Arab Journal of Nuclear Science and Applications 46 (2013) 226.

[12] A.M. PEl-Khayatt, "NXcom-A Program for Calculating Attenuation Coefficients of Fast Neutrons and Gamma-rays", Annals of Nuclear Energy 38 (2011) 128

[13] V. Harish, N. Nagaiah, T. Niranjana \& H. G. H. Kumar, "Lead oxides filled isothalic resin Polymer Composites for Gamma Radiation Shielding Applications", India Journal of pure \& Applied Physics 50 (2012) 847.

[14] V. Harish, N. Nagaiah, T. Niranjana, K. Prabhu \& T. Varughese, "Preparation and Characterization of Lead Monoxide Filled Unsaturated Polyester Based Polymer Composites for Gamma Radiation Shielding Applications", Journal of Applied Polymer Science 112 (2009) 1503.

[15] S. A. Hashemi, S. M. Mousavi, R. Faghihi, M. A. S. Sina \& A. M. Amani, "Lead oxide decorated Graphene Oxide/Epoxy Composite towards XRay Radiation Shielding”, Radiation Physics and Chemistry 146 (2018) 77.

[16] H. S. Husain, Rasheed, N. A. Naji \& B. M. Mahmood, "Investigation of Gamma Ray Shielding by Polymer Composites", IOP Conf. Series: Materials Science and Engineering 454 (2018) 012131.

[17] Z. Li, S. Chen, S. Nambiar, S. Sun, Y. Zhang, M. Zheng \& J.T. Yeow, "PMMA/MWCNT Nanocomposite For Proton Radiation Shielding Applications", Nanotechnology 27 (2016) 23.

[18] S. Malekie \& N. Hajiloo, "Comparative Study of Micro and Nano Size WO3/E44 Epoxy Composite as Gamma Radiation Shielding Using MCNP and Experiment", Chinese Physics Letters 34 (2017) 108102.

[19] P. Meshram, S. Sahu, Z. Ansari Mohd \& S. Mukherjee, "Study on Mechanical Properties of Epoxy and Nylon/Epoxy Composite", Materials Today: Proceedings 5 (2018) 5925.

[20] R. Mirj \& B. Lobo, "Radiation shielding materials: A Brief Review on Methods, Scope and Significance", Conference Paper, Jabin Science College, Huballi, India 1 (2017) 96.

[21] N. Saba, M. Jawaid, O. Y. Alothman, M. T. Paridah \& A. Hassan, "Recent Advances in Epoxy Resin, Natural Fiber-Reinforced Epoxy Composites and their Applications", Journal of Reinforced Plastics and Composites 1 (2015) 1.

[22] K. J. Singh, K. Singh \& H. Singh, "Gamma-ray Attenuation Studies of PbO. BaO.B2O3 glass system”, Radiation Measurements 41 (2006) 84.

[23] F. Sudbrock, K. Hurhan, A. Rimpler \& H. Schicha, Dose and Dose rate Measurement for Radiation Exposure Scenario in Medicine, Oramed, Barcelona, (2011).

[24] G. ALMisned, F. Akman, W. S. AbuShanab, H. O. Tekin, M. R. Kaçal, S.A.M. Issa, H. Polat, M. Oltulu, A. Ene, \& H.M.H. Zakaly, "Novel $\mathrm{Cu} / \mathrm{Zn}$ Reinforced Polymer Composites: Experimental Characterization for Radiation Protection Effciency (RPE) and Shielding Properties for Alpha, Proton, Neutron, and Gamma Radiations", Polymers 13 (2021) 3157, https://doi.org/10.3390/ polym13183157.

[25] Vasiliy Cherkasov, Valeriy Avdonin, Yuriy Yurkin \& Dmitrii Suntsov, "Prediction of Radiation Shielding Properties of Self Adhesive Elastic Coating", Materials Physics and Mechanics 42 (2019) 825. 